\title{
Hardware Implementation of Overvoltage and Under voltage Protection
}

\author{
Manish Paul $^{1}$, Antara Chaudhury ${ }^{2}$, Snigdha Saikia ${ }^{3}$ \\ Assistant Professor, Electrical Engineering Dept, Girijananda Chowdhury Institute of Management and Technology, \\ Guwahati, India ${ }^{1}$
}

Student, Electrical Engineering Dept, Girijananda Chowdhury Institute of Management and Technology,

Guwahati, India ${ }^{2,3}$

\begin{abstract}
The aim of the project is to make a low voltage and high voltage indicator. The system will save costly electrical and electronic appliances from the adverse effects of very high and very low mains voltages. A project has been proposed on simulating a overvoltage and under-voltage protector, with the hardware. The advantages of our project are -Wide single supply voltage range $2.0 \mathrm{~V}$ DC to $36 \mathrm{~V} \mathrm{DC}$, Very low supply current drain $(0.8 \mathrm{~mA})$ independent of supply voltage, low input biasing current $25 \mathrm{~mA}$.,Input common mode voltage range includes ground, differential input voltage range equal to the power supply voltage.
\end{abstract}

Keywords: Power Quality, Overvoltage, Undervoltage.

\section{INTRODUCTION}

A Overvoltage is defined as an increase in the r.m.s. value Electric Power Quality," IEEE Std. 1159-1995, of the voltage up to a level between $1.1 \mathrm{pu}$ to $1.8 \mathrm{pu}$ at June1995[2], Power quality is defined as "The concept of power frequency for periods ranging from a half cycle to a powering and grounding sensitive electronic equipment in minute and a voltage which is below the optimum a manner suitable for the equipment". operational or rated value of a component, circuit or device is called an under voltage. Such a voltage may produce for instance a malfunction or failure of customer equipments. In computers and similar devices, under voltages can lead to data losses.

Protection against sudden overv oltages in substations is a vital part of the overall reliability of power systems. The degree of surge protection afforded to a station is governed by the reliability required and the economics to obtain such reliability. Since major stations generally include strategic and highly valuable power equipment, surge protection is essential to avoid or minimize major system disturbances as well as major equipment failures. Transient overvoltage occurring in our power system can cause operational breakdown and also cause failure in industrial and household equipments as well.

In the last few decade power quality has become an important issue since many equipments are semiconductor based and controlling is done with power electronic equipments. All the equipments were heating, lighting and motors, which were not very sensitive to voltage variation. In the past the term reliability and quality was same as because there were no power electronic equipments and all the equipments were linear in natureCauses of Power Quality Problem

Some common disturbances which may cause power quality problems are listed below:

- Operation of non-linear and unbalanced loads,

- Failure of equipment, e.g. transformers and cables,

- Wrong maneuvers in distribution substations and plants. Transient overvoltages in power systems may be caused - Lightning and natural phenomena, due to several reasons of which those occurring due to - Formation of snow on transmission line, storm etc. lightning strikes or switching operations of inductive or - Energization of capacitor banks and transformers, capacitive loads. The substations are protected in such a way that lightning never falls directly 2 over it, rather the travelling waves arising due to lightning at a distant point far from the substation, travels into the substation through the towers and incoming transmission lines.

Given the course of the thesis, a study of the transient overvoltages and undervoltage and its corresponding effects on the substation and household equipments is carried out and modeled in hardware, including the protection of the device.

\section{POWER QUALITY AND ITS PROBLEMS}

According to Institute of Electrical and Electronic Engineers (IEEE) Recommended Practice for Monitoring

- Switching or start-up of large loads e.g. Induction motors

In systems where overhead lines are predominant, natural phenomena are responsible for the majority of faults in transmission and distribution systems, especially lightning [2,3]. In principle, a lightning stroke is a transient increase in the voltage along the line. However, an arc is created between the phase hit by the stroke and ground and consequently the voltage is depressed to zero.

When unbalanced loading is done on a system it causes an unbalance voltage in the phases, which ultimately creates power quality problem. This unbalance voltage 
increases rotor heating due to negative sequence magnetic flux generated in the stator winding.

The main cause of power quality problem is the short circuit fault occurring in the distribution side. This short circuit can cause a huge increase in the system current and consequently a large voltage drop in the impedance of the supply system [1].

\section{A. Effects of Power Quality Problem}

Poor electric power quality has many harmful effects on power system devices and consumer goods. Even if there is no occurrence of failure of the equipment, there will be losses and heating in the equipment which will ultimately reduce the life span of the equipment. These effects are so dangerous that it is not visible until failure occurs in the equipments.

- $\quad$ The effects of poor power quality on capacitors, rotating machines, cables and transformers, fuses, and customers' equipment creates heating, noise, poor performance etc.

- $\quad$ Premature failure of distribution transformer due to heating can be caused by harmonics.

- Due to sudden rise in voltage and/or current, failure of power system components and customer loads can occur.

- When harmonics are added to the supply voltage equipment could receive high value of instantaneous voltage and may be susceptible to failure. This high voltage may also force electronic components of power system to operate in the saturation, producing additional harmonics and disturbances.

\section{OVERVOLTAGE}

A Overvoltage is defined as an increase in the r.m.s. value of the voltage up to a level between $1.1 \mathrm{pu}$ to $1.8 \mathrm{pu}$ at power frequency for periods ranging from a half cycle to a minute as shown in fig. 2 .

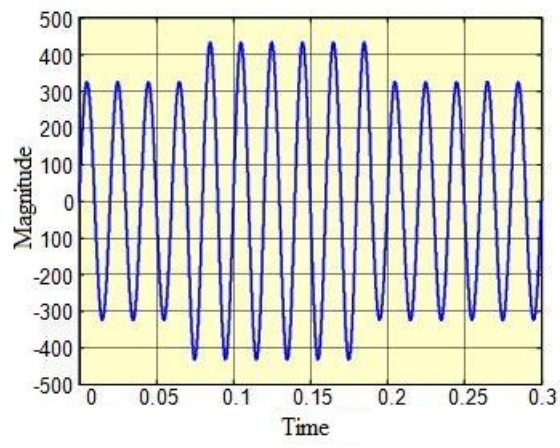

Fig. 1: Overvoltage

Overvoltage are less common than undervoltage but they also arise due to system faults. Overvoltage can occur due to single line to ground fault, which in turn will raise the voltage of the other phases. It can also cause due to disconnection of heavy industrial loads or switching on the capacitor banks [2]. This is generally due to ungrounded or floating ground delta systems, where a change in ground reference would give voltage rise to the ungrounded system.

Table II

Classification of overvoltage according to IEEE 1159

\begin{tabular}{|l|l|l|}
\hline \multicolumn{4}{|c|}{ Classification of overvoltage according to IEEE 1159 } \\
\begin{tabular}{|l|l|l|} 
Type of \\
Overvoltage
\end{tabular} & Duration & Magnitude \\
\hline Instantaneous & $\begin{array}{l}0.5-30 \\
\text { cycles }\end{array}$ & $\begin{array}{l}1.1- \\
\text { p.u. }\end{array}$ \\
\hline Momentary & $\begin{array}{l}30 \text { cycles }-3 \\
\text { secs }\end{array}$ & $\begin{array}{l}1.1- \\
\text { p.u. }\end{array}$ \\
\hline Temporary & 3 secs -1 min & $\begin{array}{l}1.1- \\
\text { p.u. }\end{array}$ \\
\hline
\end{tabular}

Causes of overvoltage are mainly due to energization of capacitor bank. It can also be generated by sudden load deduction. Due to the disconnection of load there is a sudden reduction of current, which will give rise the voltage,

$$
v=L \frac{d i}{d t},
$$

where $\mathrm{L}$ is the inductance of the line.

The effects of overvoltage are more severe and destructive. It may cause the electrical equipment to fail, due to overheating caused by high voltage. Also electronic and other sensitive equipment are prone to malfunction.

\section{UNDERVOLTAGE}

Under voltage is defined as a sudden drop in the root mean square (r.m.s.) voltage and is usually characterized by the remaining (retained) voltage. Undervoltage is thus, short duration reduction in r.m.s. voltage, caused mainly by short circuits, starting of large motors and equipment failures.

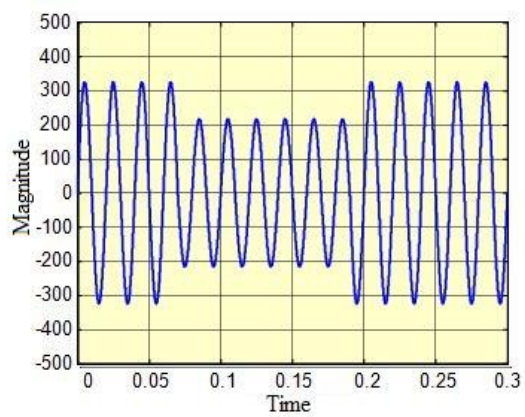

Fig. 2.Undervoltage

Furthermore, Undervoltage may be classified by their duration as shown in Table-1.

TABLE II

Classification of Undervoltage according to IEEE

\begin{tabular}{|l|l|l|}
\hline \multicolumn{2}{|c|}{ Classification of Undervoltage according to IEEE } \\
$\begin{array}{l}\text { Type of } \\
\text { Overvoltage }\end{array}$ & Duration & Magnitude \\
\hline Instantaneous & $0.5-30$ cycles & $0.1-0.9$ p.u. \\
\hline Momentary & $\begin{array}{l}30 \text { cycles }-3 \\
\text { secs }\end{array}$ & $0.1-0.9$ p.u. \\
\hline Temporary & 3 secs -1 min & $0.1-0.9 p . u$. \\
\hline
\end{tabular}


Under voltages are the most common power disturbance whose effect is quite severe especially in industrial and large commercial customers such as the damage of the sensitivity equipments and loss of daily productions and finances. The examples of the sensitive equipments are Programmable Logic Controller (PLC), Adjustable Speed Drive (ASD) and Chiller control. Undervoltage at the equipment terminal can be due to a short circuit fault hundreds of kilometers away in the transmission system.

\section{A. Causes of Undervoltage}

There are various causes for which undervoltage is created in system voltage:

1. Closing and Opening of Circuit Breakers: When the circuit breaker of a phase is opened suddenly, then the line which it is feeding will be temporarily disconnected. The other feeder lines from the same substation system will act as aundervoltage.

2. Due to Fault: Undervoltage due to fault can be critical to the operation of a power plant. The magnitude of undervoltage can be equal in each phase or unequal respectively and it depends on the nature of the fault whether it is symmetrical or unsymmetrical.

3. Due to Motor Starting: Undervoltage due to motor starting are symmetrical since the induction motors are balanced three phase loads, this will draw approximately the same high starting current in all the phases.

4. Due to Transformer Energizing: There are mainly two causes of undervoltage due to transformer energizing. One is normal system operations which include manual energizing of a transformer and another is the reclosing actions. These undervoltages are unsymmetrical in nature.

5. Equipment Failure: Failure of electrical equipment occurs due to insulation breakdown or heating or short circuit etc.

6. Bad Weather: Lightning strikes in the power line cause a significant number of undervoltages. A line to ground fault occurs when lightning strikes the line and continues to ground.

7. Pollution: Flash over takes place when there is storm in the coastal regions, where the power line is covered with salt. This salt formation acts as a good conductor of electricity and faults occur.

8. Construction Activity: Generally all power lines are undergrounded in urban areas, digging for doing foundation work of buildings can cause damage to underground cables and create undervoltages.

B. How undervoltage can be prevented

An underground voltage relay which removes a motor from service when low-voltage condition develops, so that the motor will not draw excessive current, or which prevents a large induction or synchronous motor from starting under low-voltage condition.
V. CIRCUIT DIAGRAM OF THE HARDWARE MODEL

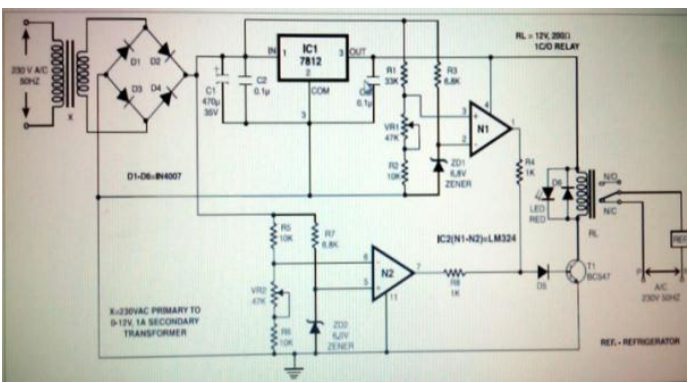

Fig 3: Circuit Diagram

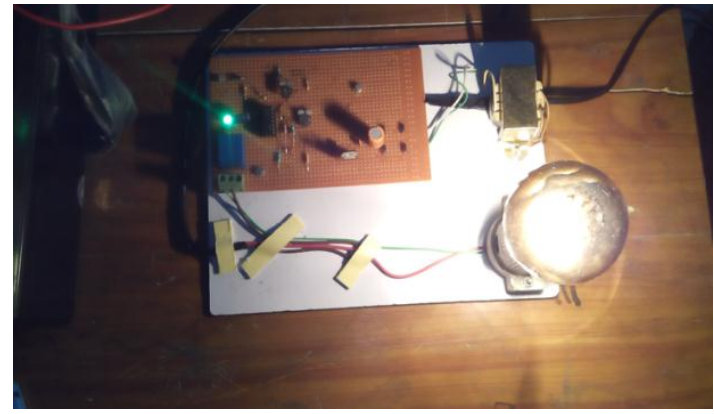

Fig 4: Hardware Model

\section{HARDWARE DESIGNING AND OUTPUT} RESULTS

This circuit protects refrigerators and other electronics appliances from over and under voltages. By the name itself we can say that if the input voltage is more or less than the required voltage then the electrical appliance gets turned off and it gets disconnected from its respective power supply. This voltage protection circuit is designed to develop a low voltage and high voltage tripping mechanism to protect a load from any damage. In many of the homes and industries fluctuation in AC mains supply take place frequently. The electronic devices get easily damaged due to the fluctuations. To overcome this problem, we can implement a tripping mechanism of under/over voltage protection circuit to protect the loads from undue damage.

\begin{tabular}{|l|l|}
\hline Source & $230 \mathrm{~V}, 50 \mathrm{~Hz}$, \\
\hline Single phase transformer & Ideal, K=23:1 \\
\hline Single phase diode bridge & Ideal \\
\hline Capacitor & $0.019 \mu \mathrm{F}$ \\
\hline Resistive load & $120 \Omega$ \\
\hline $\begin{array}{l}\text { D.C. voltage source (Relay } \\
\text { operation) }\end{array}$ & $12 \mathrm{~V}$ \\
\hline $\begin{array}{l}\text { Relay with 1 NO and 1 NC } \\
\text { changeover switches. }\end{array}$ & $\begin{array}{l}\text { Coil voltage= 12 V, } \\
\text { Operating voltage= } \\
10 \mathrm{~V}\end{array}$ \\
\hline
\end{tabular}

TABLE III The specification of the test system 
A.

RESISTIVE LOAD

The design of hardware for resistive load is done by connecting a bulb of 50 Watt. The bulb glows in the limit of $150 \mathrm{~V}$ to $230 \mathrm{~V}$. If the voltage goes down below $150 \mathrm{~V}$ than it is a case of undervoltage and if it exceeds $230 \mathrm{~V}$ than it is a condition of over voltage. The limits of operating voltage can be changed using the two potentiometers connected in the hardware. . So the relay allows the supply voltage to be fed to the load.

OPERATING VOLTAGE: (150-230)V

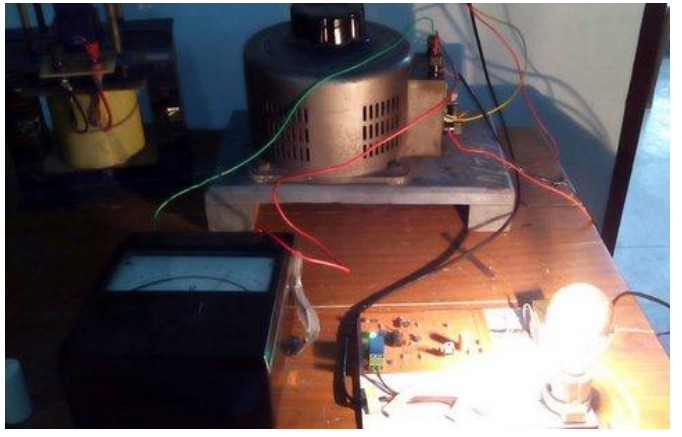

Fig 5: Hardware output for resistive load.

UNDERVOLTAGE: $(<150 \mathrm{~V})$

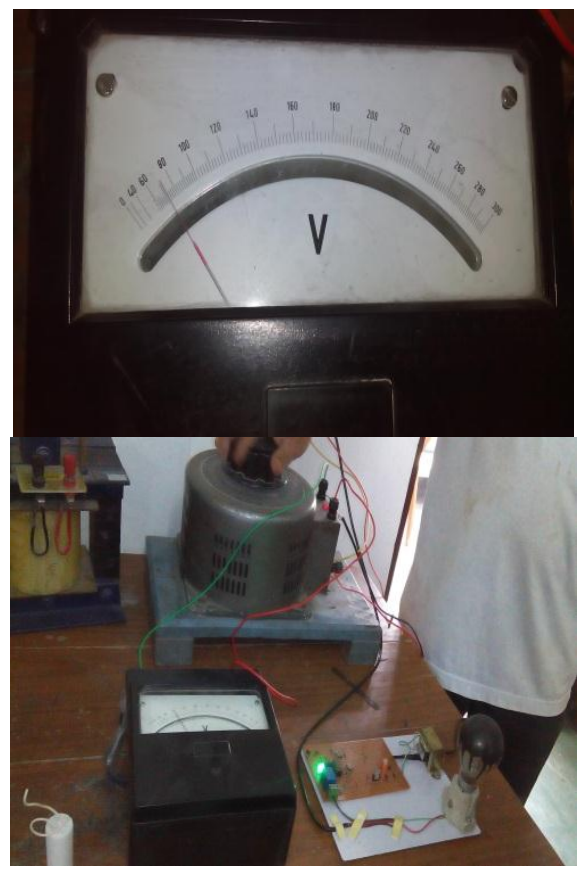

OVER VOLTAGE(>230V)

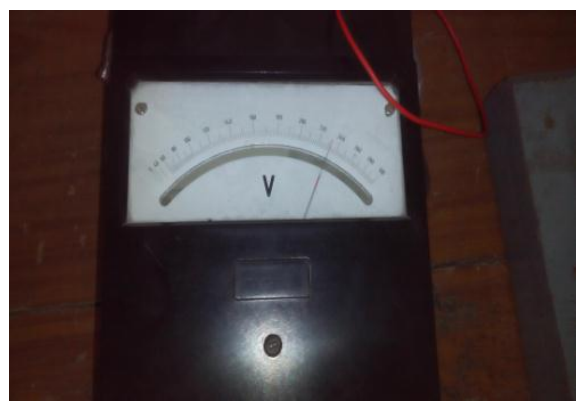

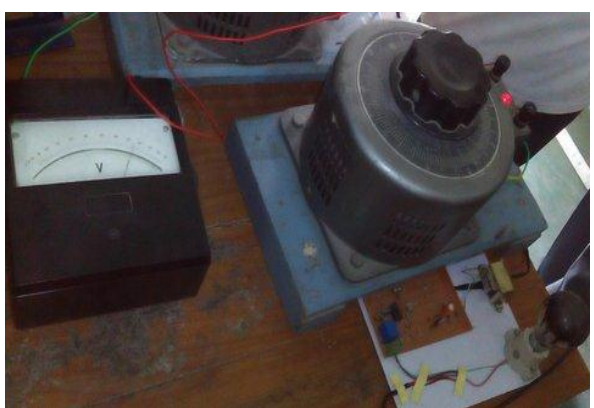

\section{B. CAPACITIVE LOAD}

The design of hardware for capacitive load is done by connecting a capacitor of $2.50 \mu \mathrm{F} \pm 5 \%$. The LED glows in the limit of $148 \mathrm{~V}$ to $200 \mathrm{~V}$. If the voltage goes down below $148 \mathrm{~V}$ than it is a case of undervoltage and if it exceeds $200 \mathrm{~V}$ than it is a condition of over voltage. The limits of operating voltage can be changed using the two potentiometers connected in the hardware.

\section{INDUCTIVE LOAD}

The design of hardware for inductive load is done by connecting a choke coil. The LED glows in the limit of $148 \mathrm{~V}$ to $230 \mathrm{~V}$. If the voltage goes down below $148 \mathrm{~V}$ than it is a case of undervoltage and if it exceeds $230 \mathrm{~V}$ than it is a condition of over voltage. The limits of operating voltage can be changed using the two potentiometers connected in the hardware.

\section{CONCLUSION}

It has been discussed that undervoltage and overvoltage problem are very common and can create problem for consumer good and industrial application. So a system has been modeled using relay and comparator and it is found to be good in disconnecting the supply when if sees any of the above problems.

\section{FUTURE SCOPE OF DEVELOPMENT}

Apart from the simulation of the software of this project in PSIM we can further extend or upgrade the operation of this protection device in the following ways:

1) Although we are applying 1 phase power supply in the prepared hardware, the implementation of the hardware can also be done applying 3 phase power supply.

2) The concept in future can be extended by integrating an alarm which sounds when voltage fluctuations occur.

It can also be interfaced with a GSM modem to convey alert message to the user via sms to take appropriate actions.

\section{ACKNOWLEDGMENT}

I would like to thank my parents and my supervisor who has helped me in all possible ways towards successful completion of this work. 


\section{REFERENCES}

[1] G. Yaleinkaya, M. H. J. Bollen and P.A. Crossley (1999), "Characterization of voltage sags in industrial distribution systems", IEEE transactions on industry applications, vol.34, no. 4, pp. 682-688, July/August.

[2] "IEEE Recommended Practice for Monitoring Electric Power Quality," IEEE Std. 1159-1995, June 1995.

[3] G.A. Taylor, A.B. Burden (1997), "Wide Area Power Quality Decision Processes and Options for Sensitive Users", Proceedings of the 14th International Conference and Exhibition on Electricity Distribution (CIRED'97), pp. 2.30.1-2.30.5, Birmingham, UK, June.

\section{BIOGRAPHIES}

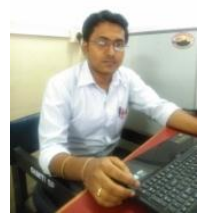

Manish Paul Author has M.Tech degree in Power Electronics and Drives from NIT Agartala, 2014. He has completed his B.Tech Degree from NERIST in 2010. He also has a industry experience as Site Engineer in Energy Infratech Pvt. Ltd. from 2010-2012, which was undergoing a construction of 1200MW Hydro Power Project in Sikkim.

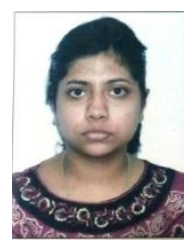

Antara Chaudhury Author is a final year student of GirijanandaChowdhury Institute of Management and Technology, affiliated under Gauhati University and has completed her degree in 2015 .She also has a good academic performance and won many prizes in school as well as in college.



Snigdha Saikia Author is a final year student of GirijanandaChowdhury Institute of Management and Technology, affiliated under Gauhati University and has completed her degree in 2015 .She also has a good academic performance and won many prizes curricular and co-curricular activities held in college college. 